\title{
Universidades Corporativas: Discussão e Proposta de uma Definição
}

\author{
Cristiane Alperstedt
}

\section{RESUMO}

$\mathrm{O}$ artigo discorre a respeito das universidades corporativas e suas características, enfocando um critério duplo de diferenciação entre universidades corporativas e departamentos de treinamento e desenvolvimento, com o objetivo de propor uma definição para as universidades corporativas a partir das distinções emergentes dessa discussão. Por se tratar de um tema cujo conhecimento é incipiente, o estudo se caracteriza como exploratório. A definição proposta para as universidades corporativas é sustentada com base em três características concomitantes: desenvolvimento de competências essenciais ao negócio da empresa, não restrição dos serviços educacionais aos funcionários, e estabelecimento de parcerias com instituições de ensino superior ou a conferição de diplomas de forma independente.

Palavras-chaves: universidades corporativas; departamentos de treinamento e desenvolvimento; aprendizagem organizacional.

\begin{abstract}
The paper discusses corporate universities and their characteristics. It's emphasized a double criterion of differentiation between corporate universities and training and development departments, looking forward to propose a definition for corporate universities based on this distinction. The study is characterized as an exploratory one once the knowledge about corporate universities is incipient. The definition proposed for corporate universities is based on three concomitants characteristics: development of core competencies to the business, non restriction of educational services to employees, and establishment of partnerships with higher education institutions or degree granting independently.
\end{abstract}

Key words: corporate universities; training and development departments; organizational learning. 


\section{INTRODUÇÃO}

Universidades corporativas já são realidade no Brasil e vêm multiplicando-se de maneira progressiva, despertando a atenção e o interesse de profissionais e acadêmicos. Por se tratar de uma expressão nova, com forte apelo mercadológico, tem sido empregada de maneira indiscriminada por diferentes organizações, $\mathrm{o}$ que tem gerado uma série de questionamentos.

O objetivo deste estudo é discorrer a respeito das universidades corporativas, adotando um duplo critério de diferenciação entre universidades corporativas e departamentos de treinamento e desenvolvimento. Tal exercício, que culmina com uma proposta de definição para as universidades corporativas, é necessariamente anterior a discussões mais profundas voltadas, por exemplo, à compreensão do papel das universidades corporativas no contexto do ensino superior. Em função da magnitude dessa discussão, que agregaria novo objetivo, e da necessidade de uma definição prévia das universidades corporativas, considerando ainda que o desenvolvimento do conhecimento se dá de maneira incremental, optouse nesse estudo pela concentração dos esforços na proposição de uma definição para as universidades corporativas. A partir desse estudo, outros são estimulados, servindo este então como ponto de partida.

Para que atenda ao objetivo a que se propõe, esse trabalho inicia-se com a discussão do processo de aprendizagem organizacional, abordando a seguir a exigência de uma nova dinâmica de aprendizagem e, na seqüência, o surgimento das universidades corporativas, sua caracterização e, finalmente, a discussão e proposta de uma definição para as universidades corporativas.

\section{O Processo de Aprendizagem Organizacional}

A questão da aprendizagem tem sido amplamente discutida, ocupando um espaço considerável em discussões acadêmicas e profissionais da atualidade; porém não se trata de algo totalmente novo, nem mesmo em ambientes organizacionais.

As empresas, ao longo do seu processo de crescimento e desenvolvimento, vão naturalmente criando e aprimorando conhecimentos e experiências que podem ser considerados como integrantes de um processo de aprendizagem. Várias são 
as formas de aprendizagem organizacional e muitas delas vêm sendo praticadas há algum tempo.

As empresas aprendem a operar a produção e vão melhorando os seus processos a partir de suas próprias experiências, alimentadas por informações advindas do mercado e da concorrência. De acordo com Bell (1984), este tipo de aprendizado é passivo, automático e não implica custos adicionais, sendo porém limitado.

Há, entretanto, outras formas de aprendizagem, que exigem determinação e postura ativa, envolvendo considerável esforço e investimento. São os processos de aprendizagem por meio da mudança, da análise do desempenho, do treinamento, da contratação e da busca, detalhados a seguir (Bell, 1984).

A introdução de novas tecnologias ou qualquer outro elemento que aponte a necessidade de mudança, estrutural ou processual, impele as organizações à aprendizagem. As experiências e conhecimentos, positivos ou negativos, adquiridos ao longo de processos de mudança são extremamente enriquecedores, conferindo à organização um plus que todos os processos de aprendizagem oferecem.

A análise do desempenho da organização em termos produtivos também irá conduzir à aprendizagem, não só em função da apreciação do comportamento de determinados índices que indicarão a necessidade de manutenção do processo produtivo ou sua correção, mas também como decorrência da necessidade de se buscarem índices de desempenho confiáveis e expressivos.

É evidente, porém necessário, destacar que a aprendizagem ocorre principalmente via processos de treinamento e desenvolvimento dos empregados, tanto no nível individual como de grupo. O objetivo é que o empregado seja mais produtivo; por isso se investe nele, proporcionando-lhe o desenvolvimento de habilidades técnicas, humanas e conceituais. De fato toda a bagagem de conhecimentos individuais e de grupo, adquirida com o passar dos anos, na própria organização ou fora dela, expressa um conteúdo de aprendizagem.

Daí advém outra forma de aprendizagem, que é decorrente da contratação. Para Quinn, Anderson e Finkelstein (1996) recrutar os melhores profissionais consiste em uma das best practices observadas pelas mais efetivas organizações. A empresa busca atrair indivíduos para a organização, de modo a assimilar seus conhecimentos e habilidades específicas. A mera apropriação de conhecimentos individuais, porém, não significa que a empresa está aprendendo; isso só ocorre se a empresa agregar na sua estrutura e processos o potencial representado por este indivíduo.

A aprendizagem por meio da busca é mais conhecida por meio da formação de redes de alianças e parcerias. A cooperação entre empresas com fins estratégi- 
cos, além da redução de custos e partilhamento dos riscos, das economias de escala e da união de esforços, possibilita largamente a aprendizagem, ao viabilizar o acesso a conhecimentos e recursos internamente inexistentes.

Por certo não se pode desconsiderar a avaliação de experiências e conhecimentos alheios, bem ou mal sucedidos. Os meios de comunicação freqüentemente revelam informações que podem enriquecer a aprendizagem organizacional. Outras formas de aquisição de conhecimentos acerca de processos e produtos, não apenas da concorrência, mas também de empresas de áreas diversas, podem conduzir à aprendizagem organizacional. A estratégia de inteligência competitiva, conforme denominado por Ettorre (1995), ou benchmarking, como é mais conhecida, se insere neste contexto.

Como se observa, habilidades e aprendizado sempre foram importantes, porém mudanças tecnológicas e alterações freqüentes da demanda de mercado, resultantes de uma série de forças que atuam conjuntamente sobre o ambiente macroeconômico, tornaram a velocidade do aprendizado uma questão crucial. Mais do que isso, o processo de aprendizagem deixou de ser um valor agregado para tornar-se uma estratégia de desenvolvimento organizacional, garantindo a sobrevivência da empresa.

\section{O Contexto Organizacional Atual e o Imperativo de uma Nova Dinâmica de Aprendizagem}

De fato as tendências do mundo atual têm influenciado as organizações na busca da aprendizagem. A rápida disseminação de informações e a própria renovação do conhecimento, impulsionadas pelo avanço constante da ciência e da tecnologia, têm forçado as pessoas a renovar e a adquirir novos conhecimentos, sob pena de se tornarem obsoletas.

A necessidade de aquisição e renovação dos conhecimentos é percebida de modo individual e também organizacional. As pessoas estão dispostas a desenvolver e aumentar seus estoques de conhecimento, porque percebem as potenciais ameaças do ambiente sobre a passividade intelectual, abalando principalmente questões de segurança profissional. A ampliação do quantum de conhecimento aumenta as chances de alocação e realocação no mercado de trabalho.

Igualmente as empresas precisam constantemente renovar e ampliar seus conhecimentos em função da necessidade de se adaptarem às freqüentes mudanças do meio externo; porém a agilidade reativa não é suficiente. Não basta buscar a 
adaptação a partir de mudanças no ambiente; a organização deve promover sua capacidade de inovar constantemente, caracterizando uma postura proativa.

Observando-se o caso do Brasil, constata-se que inúmeras empresas nacionais encontram-se atualmente em situação delicada em função da passividade com que vinham gerindo seus negócios. A abertura do mercado brasileiro inseriu o país num contexto globalizado, e uma série de empresas multinacionais passaram a competir com as nacionais, introduzindo estratégias arrojadas, que abalaram fortemente a maneira de pensar e agir das organizações. As posturas reativas não foram suficientes em muitos casos, em função da indisponibilidade de recursos e de tempo para resposta, levando à falência ou à venda muitas organizações.

As organizações precisam de capacidade criativa e de competências para se tornarem mais ágeis. Não só em termos de capacidade de resposta às mudanças, mas também em termos de capacidade para estar à frente delas.

A partir do trabalho de Senge (1990) - The Fifth Discipline - a expressão learning organization se popularizou, juntamente com o reconhecimento, por grande parte das organizações, da necessidade de se tornarem organizações de aprendizagem. Essa necessidade é decorrente do entendimento de que "se o ambiente de negócios muda mais rapidamente do que o tempo de resposta natural da organização, a aceleração do aprendizado pode tornar-se um meio de os gerentes aumentarem suas habilidades em criar os resultados desejados" (Galer e Van der Heijden, 1992).

Antes de avançar, faz-se necessário destacar que a discussão sobre aprendizagem organizacional não é nova. Questões sobre o aprendizado organizacional foram lançadas originalmente por Chrys Argiris no final da década de 70. Segundo Argyris (1977) os executivos profissionais são muito hábeis no aprendizado, que ele caracteriza como single-loop e que se refere à solução de problemas, tendo como foco a identificação e correção de erros. É importante corrigir problemas, porém não é suficiente. É necessário refletir criticamente sobre o próprio comportamento e ações, questionando o modo e as razões de se fazer algo de uma determinada maneira. Argyris (1977) define este modo de aprendizado como double-loop, e sugere que é necessário às organizações desenvolverem esta capacidade.

Baseados na necessidade de transformar as organizações em organizações de aprendizagem, uma série de autores, especialmente após o boom da obra de Senge (1990), recomendam diferentes práticas para a promoção do aprendizado organizacional, todas destacando o papel da mudança e inovação organizacional. 
Esta competência para mudar e inovar implica a necessidade de a organização possuir maior expertise. Segundo Drucker (1995) "as dinâmicas do conhecimento implicam num imperativo claro: cada organização precisa embutir o gerenciamento das mudanças em sua própria estrutura". É, portanto, responsabilidade de cada organização tornar esta expertise disponível. Em outras palavras, além das pessoas estarem forçosamente motivadas a aprender, é papel das organizações contribuir e operacionalizar o aprendizado.

Uma das formas mais comuns e muito explorada por um número significativo de empresas, visando a contribuir e operacionalizar o aprendizado organizacional, é o incentivo aos empregados da busca de capacitação e atualização profissional; entretanto uma análise intensiva dessa prática no contexto atual revela que uma série de mudanças vem acontecendo nesse contexto. Se antes as empresas encaminhavam e/ou apoiavam seus funcionários para a realização de cursos variados em instituições tradicionais de ensino superior, atualmente é fato que uma série de empresas vêm disponibilizando e oferecendo seus próprios cursos, por meio do que se convencionou chamar de universidades corporativas.

\section{Universidades Corporativas: uma Prática Inovadora das Organizaçóes na Operacionalização do Aprendizado}

Algumas empresas têm empreendido ações direcionadas para a criação e o desenvolvimento de competências junto a sua força de trabalho, mediante a implantação de cursos formais pela própria organização. Margerison (1992) aponta que um número considerável de organizações criou a sua própria business school, motivadas pela convicção de que interessa à empresa integrar o trabalho e a aprendizagem de maneira mais consistente, como forma de ampliar as habilidades de seus recursos humanos, visando à continuidade da prestação de um serviço de qualidade para a empresa.

Meister (1998) reforça esta afirmação, ao apontar que a proliferação destes cursos formais pelas próprias organizações é conseqüência do crescente interesse organizacional pelo desenvolvimento permanente de empregados capacitados. Greenspan (1999) corrobora tal afirmação, discorrendo que o aumento da demanda por serviços educacionais, particularmente on-the-job training, impulsiona a proliferação das então denominadas universidades corporativas.

É fundamental destacar que a criação destes cursos formais pelas empresas, disponibilizados pelas universidades corporativas, não se restringe apenas à seara da administração e gerência; abrange a área de informática, de engenharia e 
outras áreas consideradas vitais para o tipo de negócio da empresa. Algumas universidades corporativas focam as core competencies, tais como o desenvolvimento de qualidades de liderança e a compreensão dos valores organizacionais. Outras enfatizam a aprendizagem horizontal, em que profissionais de marketing aprendem tecnologia, por exemplo. E outras enfocam a aprendizagem vertical, promovendo o aprofundamento de conhecimentos e técnicas específicas. Evidentemente, combinações entre esses tipos são muito freqüentes.

Diante da ambiência atual, caracterizada pela ampla disseminação de informações e renovação constante de conhecimentos em função do permanente avanço científico e tecnológico, a atualização e o domínio desses fatores podem ser determinantes para a empresa na agregação de valor em produtos e/ou processos, adquirindo um caráter decisivo na disputa por mercados. A iniciativa de criação de cursos próprios, portanto, é motivada por processos de mudança organizacional orientados para a busca de efetividade ou, em outras palavras, é reflexo da imperiosa promoção da aprendizagem organizacional. Meister (1999) acrescenta que tal iniciativa também se deve à frustração com a qualidade e o conteúdo da educação pós-secundária.

Este direcionamento para a aprendizagem procura tornar produtivo o empregado, preparando-o para promover a inovação e contribuir para a formação e desenvolvimento de vantagens competitivas da organização à qual pertence. Evidentemente, do ponto de vista do empregado, este investimento é positivo, sendo até tomado como um item de referência no caso de ter que decidir por uma ou outra empresa. Em alguns casos, os programas de educação e treinamento são estendidos a fornecedores, clientes, franqueados, outras empresas e público interessado em geral.

Em vários países, principalmente nos Estados Unidos, já existe uma série de organizações que vêm buscando a disseminação do aprendizado organizacional de uma maneira inovadora. Estas organizações vêm beneficiando-se dos conhecimentos e habilidades que têm ajudado a promover, a partir da criação de departamentos ou instituições voltados especificamente para este fim. Pode-se citar as empresas Motorola, Arthur Andersen, Arthur D. Little, Disney, McDonald's, Nokia, Oracle, General Electric, entre outras, como organizações que criaram centros de ensino próprios para a condução de atividades voltadas para a aprendizagem, com nomenclaturas específicas, porém classificadas de maneira geral, como universidades corporativas. Cabe destacar que, além dos Estados Unidos, as universidades corporativas também estão presentes no Canadá, Europa e América Latina.

No Brasil, algumas universidades corporativas já iniciaram as suas atividades. É o caso da Motorola, BankBoston, Algar, Brahma, McDonald's, Accor, Amil, 
Datasul, Illycafé, entre outras. Apesar de incipientes, as universidades corporativas estão se propagando, seguindo a mesma tendência americana.

O surgimento das universidades corporativas no Brasil tem provocado uma série de discussões em torno do tema. A primeira questão que emerge é conceitual: "Que é uma universidade corporativa?", seguida, via de regra, por outra questão: "Trata-se de nova roupagem para o departamento de treinamento e desenvolvimento?". São principalmente essas questões que, ao se revelarem profundamente interrelacionadas, conduzem à proposição de uma definição que permite um melhor entendimento a respeito das universidades corporativas.

A discussão das questões arroladas envolve basicamente duas perspectivas de análise. Uma perspectiva longitudinal, considerando um continuum de tempo; e uma perspectiva transversal, cujo enfoque privilegia uma análise pontual e polarizada.

Mas antes é fundamental destacar algumas características das universidades corporativas. É o que é feito a seguir.

\section{Uma Caracterização Geral das Universidades Corporativas}

O fenômeno das universidades criadas e mantidas por empresas não é tão recente. Um estudo desenvolvido pela Quality Dynamics - uma consultoria norteamericana - constatou que em 1988 havia 400 instituições deste tipo nos Estados Unidos. Em 1999 o número de universidades corporativas cresceu para quase 2.000 (Meister, 1999).

Neste contexto, as atividades de ensino dirigidas pelas empresas promovem um programa de capacitação orientado aos objetivos da organização, garantindo uma mensagem unificada e uma linguagem comum. Além da vinculação aos objetivos organizacionais, Meister (1998) destaca o caráter intensivo e permanente como características diferenciadoras do provimento educacional oferecido pelas empresas. Essas duas características revelam os dois principais objetivos das universidades corporativas: ser agente de mudanças na organização, e aumentar as qualificações, conhecimentos e competências relacionadas ao cargo.

O funcionário, por sua vez, interpreta isso como investimento em sua carreira e possibilidade de incremento do seu curriculum, cuja validade não se restringe àquele emprego. 
Antes mais presentes no setor industrial e de serviços, o conceito de universidades corporativas está alastrando-se e intensificando-se nos setores financeiro, saúde, telecomunicações e serviços públicos, setores estes que estão enfrentando competitividade crescente ou alcançaram a maturidade.

Além de estarem presentes em diferentes setores, as universidades corporativas são tão variadas quanto as organizações com as quais estão vinculadas, assumindo diferentes características. Peak (1997) discorre sobre alguns tópicos que pontuam diferentes arranjos organizacionais.

. Origem do Investimento. As universidades corporativas necessitam de investimentos significativos por parte das empresas às quais estão atreladas e, além disso, o retorno sobre estes investimentos é de difícil medição. Não surpreende, portanto, o fato de que estas iniciativas sejam encontradas mais freqüentemente em grandes organizações.

Por outro lado, alternativas vêm sendo desenvolvidas no sentido de driblar a necessidade de grandes investimentos. É o caso dos consórcios entre empresas não concorrentes que compartilham necessidades de treinamento comuns, e que se têm associado a fim de obter redução de custos.

Meister (1998) afirma que a cobrança pelo fornecimento de educação e treinamento, especialmente após a incorporação das atividades das universidades corporativas na cultura organizacional da empresa, é uma prática recorrente nas várias universidades corporativas. Não é raro que aquelas empresas organizadas por unidades estratégicas de negócio, cobrem das unidades estratégicas que demandaram seus serviços de ensino-aprendizagem, como uma forma de equilibrar seus custos.

A pesquisa realizada pela Corporate University Xchange com 100 universidades corporativas, identificou que mais da metade das universidades pesquisadas recebem recursos diretos da própria unidade de negócio, ao invés de serem financiadas totalmente por alocações da organização (Meister, 1999). A autora ressalta que a estratégia de obtenção de recursos via remuneração por serviços evolui à medida que a universidade corporativa vai amadurecendo.

Como se pode observar, a obtenção de uma nova fonte de renda também serve de elemento motivador para que as universidades corporativas passem a treinar os elementos que compõem a sua cadeia de valor. O licenciamento de programas para fornecedores e clientes tornou-se uma importante fonte de receita para as universidades corporativas que objetivam a sua independência financeira.

Embora a maioria das universidades corporativas (74\%) ainda não receba fundos de treinamentos de fontes externas, $38 \%$ das universidades objeto da pesqui- 
sa empreendida pela Corporate University Xchange pretendiam começar a cobrar pelos servicos educacionais prestados por volta do ano 2000, indicando que aquelas que ainda não se valem desta prática pretendiam fazê-lo (Meister, 1999).

. Espaço Físico. Muitas universidades corporativas contam com instalações próprias, e outras contam com as instalações de instituições de ensino superior tradicionais em regime de parceria. A Motorola University é um exemplo de universidade corporativa que conta com instalações próprias, espalhadas ao redor do mundo, incluindo a unidade instalada em Jaguariúna (SP). O mesmo vale para a Hamburguer University da McDonald's, que no Brasil está fisicamente instalada em Barueri (SP). Outro exemplo de universidade corporativa que conta com instalações físicas é a Universidade Academia de Serviços Accor, do grupo Accor, que dispõe de um campus físico em Campinas (SP).

A Southern Company College é um exemplo de universidade corporativa baseada em um sistema de consórcio que conta com instalações físicas de uma instituição de ensino superior parceira, no caso a Emory University. A Arthur D. Little School of Management utiliza atualmente o campus de uma instituição de ensino superior - o Boston College.

Muitas universidades corporativas não contam com nenhum tipo de arranjo físico concreto, pois estão baseadas em redes eletrônicas independentes de espaço físico, constituindo o que se convencionou denominar de organizações virtuais. A Service Delivery University, universidade corporativa da Fidelity Institutional Retirement Services Company (FIRSCo), a $\operatorname{SunU}$, universidade corporativa da Sun Microsystems, e a Quality Academy, universidade corporativa da Northern States Power, são exemplos de universidades corporativas totalmente virtuais. No Brasil, são exemplos de universidades corporativas virtuais a Universidade Brahma e a Escola Amil.

Outras estão num meio termo, mesclam algumas atividades presenciais com outras a distância. São inúmeras as universidades corporativas que usam mídia eletrônica para promover algumas atividades de aprendizagem. É o caso da Arthur Andersen Center for Professional Development, da Dell University, da Xerox Management Institute, da Oracle University, da University of Excellence da Sprint, entre outras.

. Créditos Reconhecidos e Outorga de Diplomas. A pesquisa desenvolvida por Meister (1998) revela que cerca de $25 \%$ das universidades corporativas oferecem créditos universitários e $40 \%$ esperam começar a criar programas que garantam créditos. Estes créditos possuem validade a partir de um acordo desenvolvido com uma instituição de ensino superior tradicional, a qual, a partir de 
critérios negociados, assume a validade dos programas desenvolvidos pelas universidades corporativas como créditos reconhecidos para a obtenção de um diploma.

O American Council of Education - órgão americano que defende os interesses da educação superior - concedeu 7.000 créditos para os programas educacionais das universidades corporativas em 1995, número equivalente a três vezes o total de créditos concedidos em 1985 (The Economist, 1995).

A AT\&T School of Business and Technology, por exemplo, estabeleceu uma parceria com a University of Phoenix, que oferece aos funcionários da AT\&T a oportunidade de continuar os seus estudos em um dos seus 51 campi e centros de aprendizagem espalhados nos Estados Unidos, reconhecendo os créditos cursados naquela universidade corporativa. Uma parceria nos mesmos moldes também foi estabelecida entre a $A T \& T$ School of Business and Technology e a St. John's University de Nova York.

Nessa linha, e visando ao oferecimento de diplomas, várias parcerias entre empresas e instituições de ensino superior tradicionais foram estabelecidas. As empresas e suas universidades corporativas per se, muitas vezes, não têm o poder de chancela de diplomas; entretanto uma instituição de ensino superior tem tal poder. Esse é, com freqüência, um dos estímulos mais significativos ao estabelecimento de parcerias.

Variados são os exemplos dessas parcerias com vistas à outorga de diplomas. O Rochester Institute of Technology (RIT) desenvolveu, em parceria com os gerentes da Xerox, um curso de graduação e um curso de master of science voltados para os empregados da Xerox (Laabs, 1993).

Algumas empresas já galgaram um degrau mais elevado: outorgam elas mesmas os seus diplomas. A Arthur D. Little, consultoria de origem americana, licenciada para atuar como instituição educacional pelo Estado de Massachusetts, USA, com autorização para conferição de diplomas pelo Board of Regents of Higher Education of the Commonwealth of Massachusetts, oferece um mestrado em administração na Arthur D. Little School of Management, acreditado por um órgão regional de acreditação americano, o New England Association of Schools and Colleges, desde 1973.

. Composição do Corpo Docente. A política de composição dos professores para ministrar estes cursos de treinamento é variável. Algumas universidades corporativas entendem que apenas professores universitários titulados podem ministrar aulas; outras utilizam executivos da empresa e/ou consultores externos como professores; e outras ainda valem-se dos próprios profissionais da empresa, depois de submetidos a treinamento para a aquisição de habilidades didáticas. 
. Clientela. Algumas das universidades corporativas extrapolam o oferecimento dos cursos de treinamento para além dos funcionários da empresa, estendendoos a clientes, fornecedores, franqueados, outras empresas, e até mesmo à comunidade externa em geral. Vale lembrar que a referência aos clientes engloba todos os intermediários no processo de venda, ou seja, revendedores, distribuidores, atacadistas e lojistas.

Tradicionalmente esta expansão para outros stakeholders é resultado do sucesso obtido pelo programa junto aos clientes internos, e motivada pela possibilidade de realocação de custos. Os programas educacionais promovidos pelas empresas, durante muito tempo considerados como mero centro de custos, passaram a ser considerados como potencial centro de lucros, constituindo-se em forma alternativa de captação de recursos financeiros para a empresa.

\section{Discussão e Proposta de uma Definição para Universidades Corporativas}

Resgata-se a partir de agora a discussão das questões lançadas anteriormente. Para que a primeira questão - "que é uma universidade corporativa?" - seja respondida, é necessário que se responda à segunda questão: "trata-se de nova roupagem para o departamento de treinamento e desenvolvimento?".

Ao observarem-se as características das universidades corporativas, percebese que estas diferem substancialmente dos tradicionais departamentos de treinamento e desenvolvimento das empresas. Com o intuito de esclarecer estas diferenças, optou-se por um critério duplo de diferenciação, explorando-se duas perspectivas de análise: longitudinal e transversal, como fios condutores auxiliares para a proposição de uma definição para as universidades corporativas.

O primeiro critério de diferenciação entre as universidades corporativas e os departamentos de treinamento e desenvolvimento de uma empresa vale-se da perspectiva longitudinal.

Uma análise longitudinal das empresas, enfocando especialmente a área de recursos humanos, revela que, segundo Fleury e Fleury (2000), a consolidação da gestão estratégica de recursos humanos na década de 90 , foi incorporando à prática organizacional o conceito de competência, como base do modelo de gestão de pessoas. Ainda que o conceito de competências não esteja acabado, devendo ser entendido como um conceito em construção (Le Borteff, 1995), mu- 
danças significativas nas práticas de gestão de pessoas em algumas empresas podem ser observadas.

É o caso do uso de novos instrumentos e técnicas que vêm sendo empregados em processos de recrutamento e seleção, visando a identificar pessoas, conforme Le Borteff (1995), com um conjunto de conhecimentos e habilidades que se transformem em saber fazer e saber agir em dado contexto profissional. Também no que compete aos sistemas de remuneração, algumas empresas têm desenvolvido modelos próprios, estabelecendo os níveis de competência e a compensação condizente com cada nível. Mais relevante ainda, considerando a perspectiva deste estudo, são os novos contornos assumidos pelos processos de treinamento e desenvolvimento, praticados pelas universidades corporativas criadas por um número cada vez mais crescente de empresas (Fleury e Fleury, 2000).

As universidades corporativas responsáveis pelo processo de desenvolvimento de pessoas alinhado à definição das estratégias de negócio e competências essenciais da organização, assumiram, em muitos casos, um papel tão significativo que, em várias empresas, a área ou departamento de recursos humanos passou a gravitar em torno de suas universidades corporativas. Os demais processos inerentes à gestão de recursos humanos foram absorvidos como subfunções ou subprocessos das universidades corporativas, denotando mudança qualitativa substancial na organização das funções estratégicas de recursos humanos. Meister (1999) corrobora esse estado das coisas, ao afirmar que, do total de universidades corporativas investigadas por ela, $63 \%$ se reportam ao gerente ou diretor de recursos humanos; porém $37 \%$ se reportam diretamente à alta cúpula da organização. Isso evidencia o novo papel assumido pelas universidades corporativas perante a área de recursos humanos e a organização como um todo.

Ainda que mudanças substanciais tenham ocorrido nesse âmbito, promovendo a reorganização das funções e processos de recursos humanos, a análise dessa perspectiva longitudinal demonstra que as universidades corporativas podem ser entendidas como evolução direta da função ou processo de treinamento e desenvolvimento.

O segundo critério de diferenciação entre as universidades corporativas e os departamentos de treinamento e desenvolvimento de uma empresa faz uso da perspectiva transversal com uma análise pontual e polarizada.

De acordo com Meister (1998) um departamento de treinamento de empresa tende a ser reativo, descentralizado e serve a ampla audiência; enquanto a universidade corporativa tem orientação proativa e centralizadora para o encaminhamento de soluções de aprendizagem para cada negócio dentro da empresa, ou seja, departamentos de treinamento em geral propõem programas de treinamento, 
à medida que estes se tornam necessários, sendo muitas vezes identificada a sua necessidade no contexto de um departamento específico, e cujos tópicos são, na maior parte das vezes, genéricos. Já nas universidades corporativas, os programas de educação e treinamento são permanentes e orientados com visão de futuro, antecipando e gerando necessidade de melhoria, privilegiando os objetivos organizacionais, ainda que orientados para cada negócio dentro da empresa. Neste sentido, conforme Gerbman (2000), as universidades corporativas têm um escopo mais estratégico, enquanto os departamentos de treinamento são mais táticos.

Outra diferença que Meister (1999) destaca é que os tradicionais departamentos de treinamento se voltam mais para as habilidades técnicas imediatamente necessárias ao trabalho, ao passo que as universidades corporativas não se restringem às habilidades técnicas; envolvem também o conhecimento de valores e da cultura da corporação, da indústria em que a empresa opera, como fornecedores, clientes e concorrentes, e das competências básicas do negócio.

Diferentemente dos tradicionais departamentos de treinamento e desenvolvimento, as universidades corporativas valem-se da sistemática universitária, oferecendo cursos em bases modulares, valendo créditos, até mesmo denominando de corpo docente o grupo de professores e instrutores. Algumas universidades corporativas contam ainda com catálogo de cursos e logotipo próprio.

Entretanto essas distinções apontadas não parecem suficientes para distinguir as chamadas universidades corporativas dos tradicionais departamentos de treinamento e desenvolvimento. Como a terminologia universidade corporativa parece estar na moda, muitas instituições estão batizando com esse nome, ou nomes similares, os seus antigos departamentos de treinamento e desenvolvimento, sem, contudo, imputar-lhes atividades diferenciadoras que justifiquem a mudança de nome. Isso tudo tem criado espaço para certa confusão.

$\mathrm{O}$ que distingue de fato as universidades corporativas dos departamentos de treinamento, considerando-se a perspectiva de análise pontual e polarizada, são duas características fundamentais, destacadas e entendidas pelo pesquisador como essenciais para a compreensão dessa distinção.

A primeira se refere ao fato de que as universidades corporativas não se restringem ao atendimento dos funcionários, prática usual dos departamentos de treinamento, podendo estender seus serviços para além das fronteiras da empresa, servindo a clientes, fornecedores, franqueados e público externo interessado em geral. Dessa distinção decorre outra, apontada por Meister (1998): os departamentos de treinamento são administrados como departamento da organização, sendo financiados inteiramente por ela e voltados exclusivamente para os funcionários; enquanto as universidades corporativas são operadas, em muitos casos, 
como uma unidade de negócio, sendo financiadas também pelos seus clientes, sejam eles funcionários, fornecedores, clientes, franqueados ou comunidade externa.

A segunda característica fundamental refere-se ao fato de que algumas universidades corporativas se têm associado a instituições de ensino superior tradicionais, estabelecendo diferentes tipos de parcerias, entre as quais se destaca a validação das disciplinas cursadas nas universidades corporativas para fins de totalização dos créditos exigidos pelas instituições de ensino superior tradicionais. E igualmente o contrário: disciplinas cursadas em instituições de ensino superior tradicionais são reconhecidas como válidas pelas universidades corporativas. Além da validação dos créditos, o estabelecimento de parceria pode ocorrer com o objetivo último de possibilitar a conferição de diploma. Isso ocorre porque, não havendo licença, no caso americano, ou credenciamento da instituição, autorização e reconhecimento do curso, no caso brasileiro, a universidade corporativa apenas tem condições de conferir diploma via instituição de ensino superior tradicional à qual está associada. Seguindo essa linha, algumas universidades corporativas americanas obtiveram licença, e passaram a conferir elas mesmas os diplomas, independentemente de parcerias com instituições de ensino superior tradicionais. Essa prática formalizada pelas universidades corporativas constitui outro aspecto fundamental que as diferencia dos tradicionais departamentos de treinamento.

Considerando-se, enfim, os dois critérios de diferenciação a partir da análise longitudinal e transversal, e em se tratando - universidades corporativas - de uma expressão nova que está sendo indistintamente utilizada, tendo significado um pouco diferente em cada empresa que a está implementando, e não existindo um conjunto de parâmetros ou regras que precisam ser seguidas (Journal of Career Planning \& Employment, 1996), o objetivo deste estudo consiste em propor uma definição para as universidades corporativas.

Assim sendo, a definição proposta para as universidades corporativas privilegia não apenas a formação estratégica de desenvolvimento de competências essenciais ao negócio da empresa, mas também, paralelamente, a detenção de duas características fundamentais destacadas: não restrição dos serviços educacionais aos funcionários, com destaque para abertura ao público externo em geral; e estabelecimento de parcerias com instituições de ensino superior, com destaque para a validação dos créditos cursados e a possibilidade de conferição de diplomas, ou a conferição de diplomas de forma independente.

Não obstante, e fundamentalmente, a definição proposta deve sempre ser trazida à baila, de modo a distinguir aquilo que vem sendo intitulado de universidades 
corporativas das universidades corporativas de fato. Procura-se destacar a necessidade de não se assumirem características iguais a instituições indistintamente denominadas universidades corporativas.

Evidentemente que, em se tratando de assunto incipiente, demandam-se estudos futuros, de forma que a discussão seja complementada e que se consolide a definição proposta.

\section{Referências Bibliográficas}

ARGYRIS, C.

On organizational learning. Cambridge: Blackwell, 1995.

BELL, M.

'Learning' and accumulation of industrial technological capacity in developing countries. In: FRANSMAN, M.; KING, K. ( O r g s . ). Te ch nologi cal capability in the third world. New York: St. Martin's Press, 1984.

CORPORATIONS GROW

THEIR OWN BEST

EMPLOYEES AT CORPORATE UNIVERSITIES.

\section{Journal of Career Planning \&}

Employment, v. 56, n. 2, p. 2426, Winter 1996.

\section{DRUCKER, P.}

Administrando em tempos de grandes mudanças. São Paulo: Pioneira, 1995.
ETTORRE, B.

Managing competitive intelligence. Management Review, v. 84, n. 10, p. 15-19, Oct. 1995.

FLEURY, A.;

FLEURY, M. T. L.

Estratégias empresariais e formação de competências: um quebra-cabeças caleidoscópico da indústria brasileira. São Paulo: Atlas, 2000.

GALER, G.;

VAN DER HEIJDEN, K.

The learning organization: how planners create organizational learning.Marketing Intelligence \& Planning, v. 10, n. 6, 1992.

GERBMAN, R. V.

Corporate universities can augment training programs and teach employees strategic lessons. HR Magazine, v. 45, n. 2, p. 101-106, Feb. 2000. 
GREENSPAN, A.

The interaction of education and economic change. The Region, v. 13, n. 1, p. 6-10, Mar. 1999.

LAABS, J. J.

Employees get their degrees on-site. Personnel Journal, v. 72, n. 6, June 1993.

LE BORTEFF, G.

De la compétence. Paris: D’Organization, 1995.

MEISTER, J.

Corporate quality universities: lessons in building a world-class work force. New York: McGraw-Hill, 1998.
Educação corporativa: a gestão do capital intelectual através das universidades corporativas. São Paulo: Makron Books, 1999.

PEAK, M. H.

Go corporate U. Management Review, v. 86, n. 2, p. 33-37, Feb. 1997.

QUINN, J. B.;

ANDERSON, P.;

FINKELSTEIN, S.

Managing professional intellect: making the most of the best. Harvard Business Review, [s.n.], p. 71-80, Mar./Apr. 1996. 